\title{
Liver Failure Occurring As a Component of Exertional Heatstroke
}

\author{
TAREK HASSANEIN, JOSHUA A. PERPER, LEWIS TEPPERMAN, \\ THOMAS E. STARZL, and DAVID H. VAN THIEL \\ Departments of Medicine and Surgery, University of Pittsburgh, and The Coroner's Office, \\ Allegheny County, Pittsburgh, Pennsylvania
}

\begin{abstract}
An unusual case of an exertional heatstroke in a healthy 25-year-old man is presented. Initially, the patient was deeply comatose and developed severe rhabdomyolysis and massive hepatic necrosis. Subsequently, he received a liver transplant with remarkable improvement in his mental status, although the rhabdomyolysis continued. The patient died 41 days after the transplant due to a complicating infection. Providing that infections can be effectively controlled, liver transplants might be a promising therapeutic alternative for the few patients who survive the initial neurological consequences of this unusual event.
\end{abstract}

A $\mathrm{n}$ outbreak of heatstroke occurred among 50 police trainees who were participating in an intense recruitment training program in Massachusetts in 1988. Each experienced a variable degree of exercise-induced rhabdomyolysis. Forty of the trainees (80\%) reported dark urine, $26(52 \%)$ experienced myoglobinuria and hemoglobinemia, and 13 (26\%) experienced kidney damage secondary to rhabdomyolysis. One recruit experienced hepatic failure and went into deep coma. This individual and his clinical course is the topic of this report.

\section{Case Report}

A previously healthy 25-year-old white man without a history of alcohol or drug use, who had been on a diet to lose weight and who had been exercising vigorously for several hours in a deconditioned state, suddenly collapsed during supervised exercise. He was admitted to a local hospital in Massachusetts, unconscious, unresponsive to deep pain, hypotensive $(70 / 0)$, hyperthermic $\left(105^{\circ} \mathrm{F}\right.$ rectal $)$, tachypneic (60/min), and with tachycardia (128/min).

He experienced seizures which were treated with diazepam and phenytoin. Thereafter, he rapidly developed multisystem organ failure manifested as disseminated intravascular coagulation (DIC), liver and renal failure, and rhabdomyolysis. Because of combined renal and hepatic failure, he was transferred to the Presbyterian University Hospital in Pittsburgh on his sixth day after heatstroke for possible liver and kidney transplantation. On admission to the intensive care unit in Pittsburgh, he was comatose (grimaced to pain), had a rectal temperature of $38.6^{\circ} \mathrm{C}$, blood pressure of $110 / 70$, heart rate of 124 , and respiratory rate of 22. His pupils were minimally reactive; gag and corneal reflexes were present but reduced; and his neck was supple. His limbs were flaccid with reduced muscle tone; deep tendon reflexes were present. His sclera were icteric. His abdomen was distended slightly but without organomegaly and ascites. Bowel sounds were reduced. Rectal examination revealed stool that was guaiac-positive. The rest of his examination was unremarkable. He was anuric $(50 \mathrm{~mL} /$ day $)$. The little urine that was collected contained $100-300$ red blood cells per high-power field, 0-2 white blood cells per high-power field, and was myoglobin-positive. The other laboratory data obtained on admission are shown in Table 1. A hepatitis profile for hepatitis $B$ virus and delta virus were negative whereas the hepatitis $A$ virus screen was positive for immunoglobulin $G$ antibody. A coagulation study was consistent with the coagulopathy of liver failure (dysfibrinogenemia, depressed coagulation factors except factor VIII, and elevated fibrin monomer/degradation products). An electroencephalogram showed marked nonspecific abnormalities of a generalized nature without any evidence of lateralization suggestive of a diffuse central nervous system disturbance $(14 \mathrm{~Hz}$ positive spikes were seen which are described in individuals with hepatic disease). A computed tomography (CT) scan of the abdomen showed the liver to be homogenous without focal abnormality. Mild ascites and bilateral pleural effusions (more on the right side than the left) and disrupted peripancreatic fat planes were evident on the CT scan. His head CT scan showed no focal abnormalities, but soft tissue swelling was noted overlying the left frontal and right posterioparietal

Abbreviations used in this paper: CT, computed tomography; DIC, disseminated intravascular coagulation; OLTx, orthotopic liver transplantation.

(C) 1991 by the American Gastroenterological Association 0016-5085/91/\$3.00 
Table 1. Laboratory Data Obtained on Admission to Hospital in Pittsburgh

\begin{tabular}{llc}
\hline \multirow{2}{*}{\multicolumn{1}{c}{ Parameters }} & \multicolumn{2}{c}{ Result } \\
\cline { 2 - 3 } & (Present unit) & (SI unit) \\
\hline Hemoglobin & $10.9 \mathrm{~g} / \mathrm{dL}$ & $109 \mathrm{~g} / \mathrm{L}$ \\
White blood cell count & $13.2 \times 10^{3} / \mathrm{mm}^{3}$ & - \\
Platelet count & $103 . \times 10^{3} / \mathrm{mm}^{3}$ & - \\
Bilirubin (total) & $25.7 \mathrm{mg} / \mathrm{dL}$ & $439 \mu \mathrm{mol} / \mathrm{L}$ \\
Bilirubin (direct) & $24.6 \mathrm{mg} / \mathrm{dL}$ & $421 \mu \mathrm{mol} / \mathrm{L}$ \\
Aspartate aminotransferase & $570 \mathrm{IU} / \mathrm{L}$ & $570 \mathrm{U} / \mathrm{L}$ \\
Alanine aminotransferase & $1226 \mathrm{IU} / \mathrm{L}$ & $1226 \mathrm{U} / \mathrm{L}$ \\
Alkaline phosphatase & $109 \mathrm{IU} / \mathrm{L}$ & $109 \mathrm{U} / \mathrm{L}$ \\
$\gamma$-glutamyl/transpeptidase & $26 \mathrm{IU} / \mathrm{L}$ & - \\
Total protein (serum) & $5.4 \mathrm{~g} / \mathrm{dL}$ & $54 \mathrm{~g} / \mathrm{L}$ \\
Albumin & $3.6 \mathrm{~g} / \mathrm{dL}$ & $36 \mathrm{~g} / \mathrm{L}$ \\
Ammonia & $186 \mu \mathrm{g} / \mathrm{dL}$ & $109 \mu \mathrm{mol} / \mathrm{L}$ \\
Amylase & $402 \mathrm{IU} / \mathrm{L}$ & $402 \mathrm{U} / \mathrm{L}$ \\
Lipase & $1582 \mathrm{IU} / \mathrm{L}$ & $1582 \mathrm{U} / \mathrm{L}$ \\
Creatinine phosphokinase & $6409 \mathrm{IU} / \mathrm{L}$ & - \\
Blood urea nitrogen & $27 \mathrm{mg} / \mathrm{dL}$ & $9.6 \mathrm{mmol} / \mathrm{L}$ \\
Creatinine & $8.1 \mathrm{mg} / \mathrm{dL}$ & $716 \mu \mathrm{mol} / \mathrm{L}$ \\
Potassium & $4.8 \mathrm{mEq} / \mathrm{L}$ & - \\
Calcium & $8.4 \mathrm{mg} / \mathrm{dL}$ & $2.09 \mathrm{mmol} / \mathrm{L}$ \\
Phosphorus & $3.3 \mathrm{mg} / \mathrm{dL}$ & - \\
\hline
\end{tabular}

bone and maxillary sinus disease and evidence of inflammation of the left parotid gland were noted.

The patient underwent a liver transplantation 1 day after referral (8th day after heatstroke). During the liver transplant operation, the pancreas was noted to be very swollen and hard, consistent with severe acute pancreatitis.

The elevated serum bilirubin level $[25.7 \mathrm{mg} / \mathrm{dL}$ (439 $\mu \mathrm{mol} / \mathrm{L})$, direct $24.6 \mathrm{mg} / \mathrm{dL}(421 \mu \mathrm{mol} / \mathrm{L})]$ rapidly decreased following orthotopic liver transplantation (OLTx) and reached a normal level 30 days after transplantation (Figure $1 A$ ). The serum alanine aminotransferase (serum glutamic pyruvic transaminase) level fell to within the normal ranges in 15 days. The serum aspartate aminotransferase (serum glutamic oxaloacetic transaminase) level returned to the normal range 19 days after transplantation (Figure $1 B$ ).

Upon histological examination, the surgically removed liver showed severe distortion of the normal architecture with centrilobular necrosis and extensive bandlike bridges

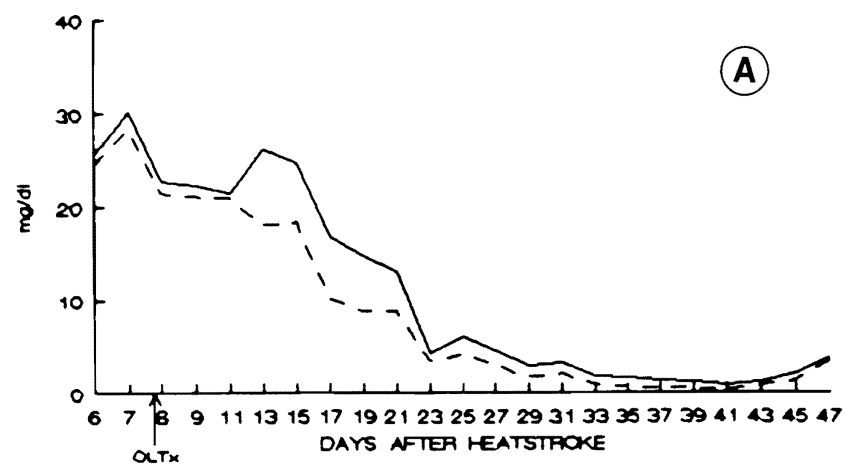

of parenchymal collapse and necrosis, infiltration with numerous acute and chronic inflammatory cells, as well as numerous macrophages that were laden with hemosiderin pigment (Figure $2 A$ ). Focal fatty change and both intracellular and intracanalicular bile stasis were present. Early regenerative changes with pseudoglandular arrangement of hepatic cells were also observed. No viral inclusions were seen.

The patient was continuously in a state of coma, able only to grimace to deep pain, but had intact brainstem reflexes before OLTx. Most reflexes were present and the plantar response was absent. On admission to the hospital, his electroencephalogram showed a diffuse central nervous system disturbance with no evidence of lateralization. Three days after liver transplantation, the patient manifested spontaneous movements of his head but had no response to pain. His electroencephalogram showed some improvement but still indicated a generalized disturbance consistent with a toxic-metabolic disorder. A cerebral blood flow study at a $\mathrm{PCO}_{2} 40$ was normal. Over the next 20 days, the patient improved dramatically. He became fully alert and able to speak. He also experienced a steady increase in his peripheral muscle strength. Suddenly, his consciousness started to deteriorate and a CT scan of his head showed an intraparenchymal blood clot in the left middle cerebellar peduncle and left cerebellar hemisphere with edema and a rightward displacement of the fourth ventricle. These findings were interpreted as being due to either a hemorrhagic infarct occurring as part of a coagulopathy resulting from renal failure or due to an infectious cerebellitis.

Because the patient's condition deteriorated so rapidly, a heroic left suboccipital craniotomy with evacuation of the clot and debridement of the infarcted cerebellum was performed. Examination of the debrided cerebellar tissue showed hemorrhagic tissue devoid of Purkinje's cells associated with Bergmann glial astrocytosis. No tumor or vascular malformation was evident. These findings, in addition to those found in muscle showing rhabdomyolysis, are consistent with heatstroke. The patient's condition continued to deteriorate and he died. An autopsy was performed. The major pathological findings at necropsy can be grouped in two major categories: (a) findings related to heatstroke injury and (b) the hepatic allograft findings.

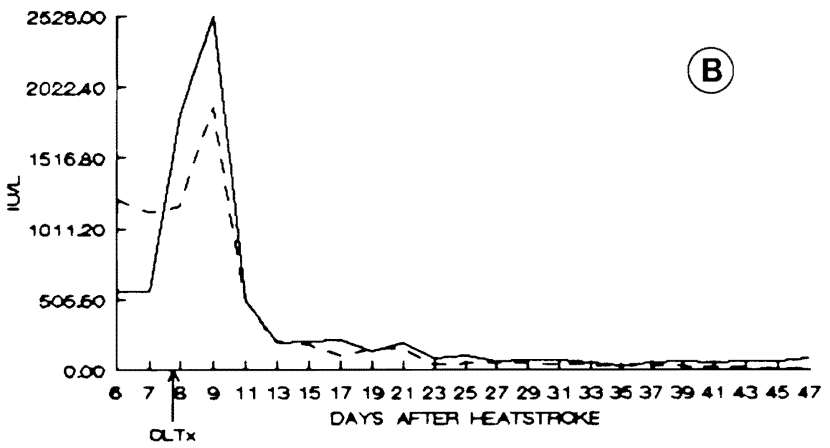

Figure 1. A. Total (-) and direct (--) serum bilirubin, showing decrease following OLTx.

$B$. Serum ALT (- ) and AST (-) both peaked on the first day post-OLTx and decreased thereafter and returned to normal values on the 15th and 19th day, respectively, after OLTx. 

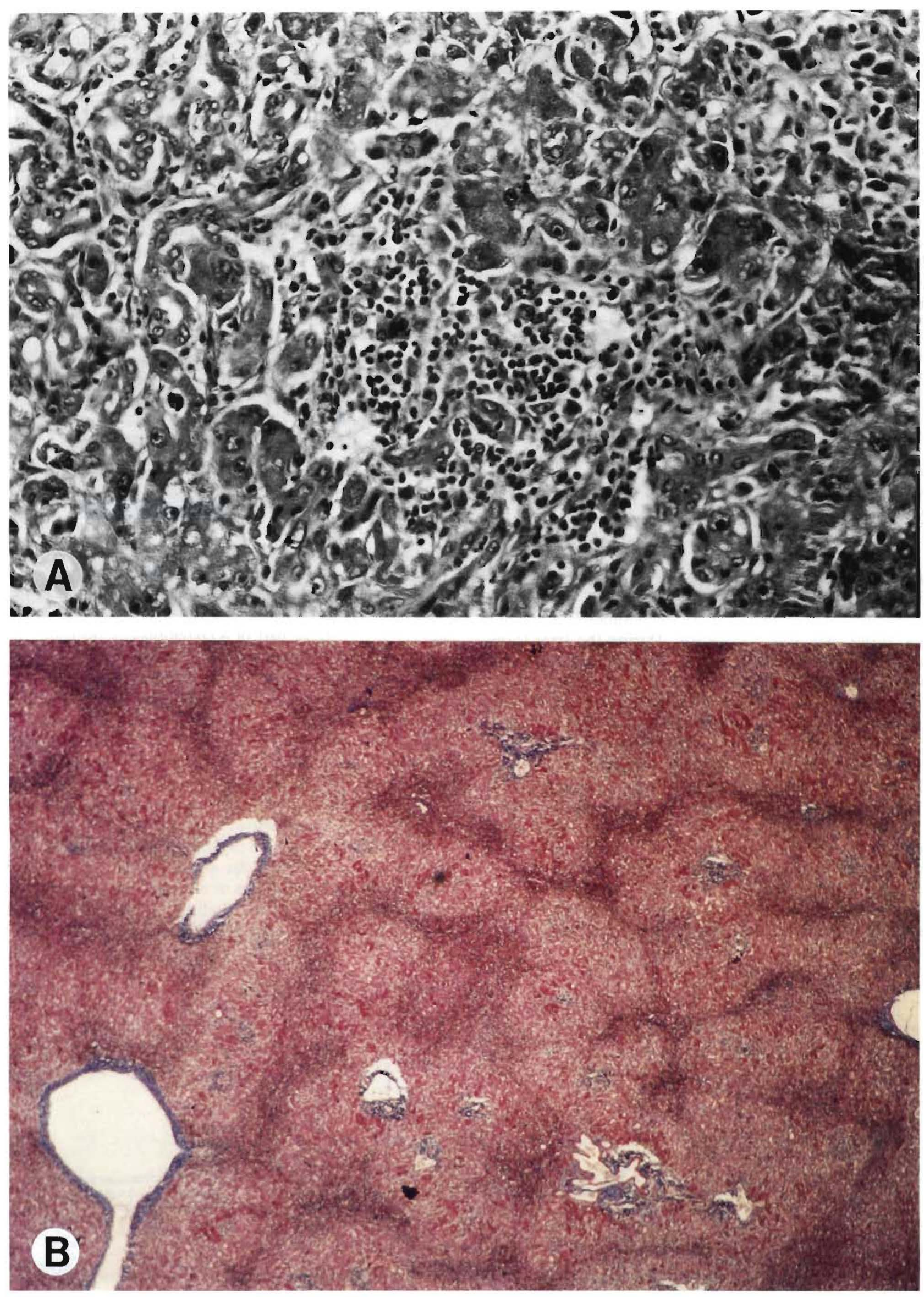


\section{Heatstroke-Related Injuries}

Muscular damage. Both the upper and lower muscles of locomotion showed severe, extensive necrosis with shrinkage and striking yellow-green discoloration (Figure $3 A$ and $B$ ). Microscopically, wide areas of necrotic muscle and severe calcification were observed (Figure $3 C$ ). In contrast, the other peripheral striated muscles such as the pectoral or intercostal muscles were virtually unaffected.

Central nervous system findings. Marked loss of Purkinje's cells of the cerebellum.

\section{Hepatic Findings}

The liver allograft was remarkable for the presence of two small subcapsular infarcts.

\section{Discussion}

This case demonstrates a number of unusual clinical and pathological features. The individual herein reported was a dehydrated, nonacclimatized, and undertrained individual who underwent vigorous exercise in a training program under moderate climatic conditions. Each of these factors that individually predisposed this particular individual to heatstroke were bound to lead in aggregate to a rapid demise, which was substantially delayed only by the transplant intervention.

This tragic situation occurred as part of a training program of police recruits where the recruits were required to perform heavy exercise before being trained and acclimatized. They had all been exercising vigorously at an ambient temperature of $80^{\circ}-83^{\circ} \mathrm{F}\left(25^{\circ} \mathrm{C}\right)$, not high enough by itself to cause heatstroke, but sufficient to induce critical water loss. Although all 50 cadets were trained under identical environmental conditions, their clinical presentations varied depending on their degree of hydration, acclimatization, and their level of physical fitness before training. Only this one case developed severe hepatic injury. A thorough investigation by the local health authority did not show an infectious or toxic origin for the illness experienced by these recruits or any evidence of toxin or drug injection by the individual described in this report.

The onset of the illness in this individual was characteristic, in almost every respect, of classical cases of exertional heatstroke because the patient presented with a sudden collapse, convulsions, hy- potension, and a markedly elevated rectal temperature $(1,2)$.

The rhabdomyolytic muscular changes and severe pathological changes in the native liver were both consistent with a heatstroke-related injury. The primary involvement of the muscles of locomotion is explainable on the basis that they were the muscles overexerted during the training process.

The liver transplant procedure and other modern life-sustaining procedures used in this case substantially prolonged the survival period and permitted the development of a peripheral muscle injury of an unprecedented extent and severity.

The neuronal cerebellar damage found is an excellent marker of the heatstroke pathology and its severity and can easily be differentiated from all other conditions such as global brain ischemia, pontocerebellar degeneration, and Friedreich ataxia (3). In global brain ischemia, the process involves the entire brain whereas in the latter conditions, the cerebellar damage is much more restricted within the cerebellum than in heatstroke.

The extensive necrosis of the skeletal muscles present in this case triggered a severe degree of hypocalcemia as a result of dystrophic topical calcification. The coexistent severe pancreatitis also aggravated the hypocalcemia as did the related hyperphosphatemia.

As exemplified in this case report, the liver is occasionally injured in exertional heatstroke (1). Although hepatic failure is seldom described in heatstroke patients, it was dramatically evident in this patient. The liver histology at the time of OLTx procedure (8th day after heatstroke) was consistent with that reported in other cases (4-9).

The severe central nervous system dysfunction seen in this case improved dramatically after OLTx. Over the subsequent several days, it improved to the point that the patient was able to sit up, talk, and respond appropriately to his surroundings 7 days post-OLTx.

When it occurs in cases of heatstroke, death either occurs early during the first several days as a consequence of central nervous system injury or later as a result of renal failure, liver failure, myocardial infarction, or vascular thrombosis (10). The patient herein described survived the early period and developed severe hepatic failure which was reversed by OLTx. Unfortunately, systemic infection due to fungal and

Figure 2. $A$. Liver with dark bands of hepatic necrosis and collapse mimicking cirrhosis (H\&E; original magnification $\times 80$ ).

$B$. Microphotograph of native liver after heatstroke mimicking cirrhosis. However, the darker reddish parenchymal zones, demarcating pseudolobules, are not collagenous but are areas of necrosis and collapse (Masson; original magnification $\times 5$ ). 

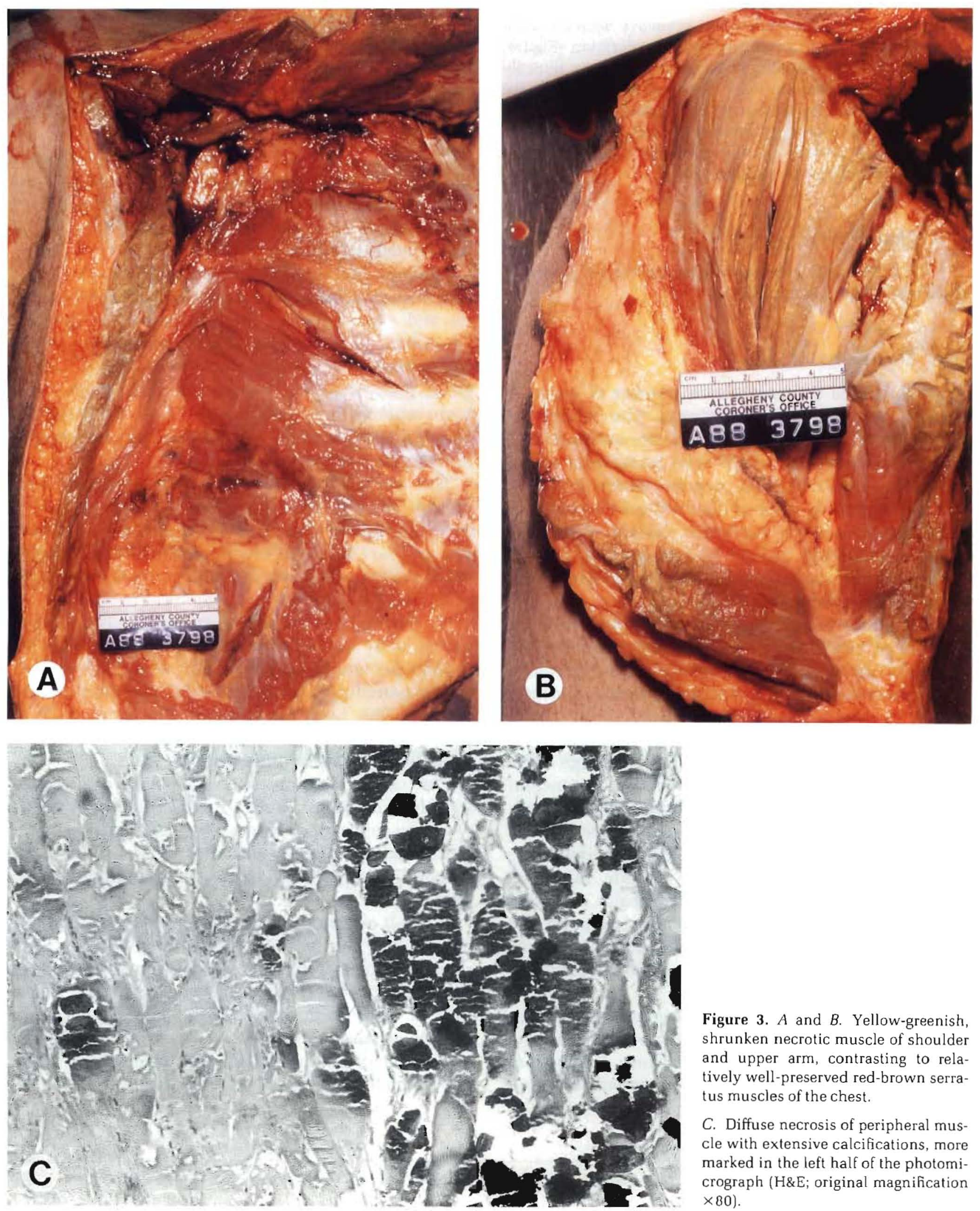

Figure 3. $A$ and $B$. Yellow-greenish, shrunken necrotic muscle of shoulder and upper arm, contrasting to relatively well-preserved red-brown serratus muscles of the chest.

C. Diffuse necrosis of peripheral muscle with extensive calcifications, more marked in the left half of the photomicrograph (H\&E; original magnification $\times 80$ ). 
bacterial sepsis caused his death. It is interesting to note in this regard that prior case reports have documented a high prevalence of Candida spp. infections in heatstroke victims (11).

The most important consideration in heatstroke is its prevention. Should it occur, however, the cornerstone of its successful treatment is early and effective elimination of hyperthermia. Liver transplantation should be considered for those few patients who survive the initial neurological injury and develop potentially fatal liver damage.

\section{References}

1. Hassanein T, Razack A, Gavaler JS, Van Thiel DH. Heatstroke: its clinical and pathological presentation, with particular attention to the liver. Dig Dis Sci (in press).

2. Shibolet S, Coll R, Gilat T, Sohar E. Heat stroke: its clinical and mechanism in 36 cases. QJ Med 1967;36:525-548.

3. Malamud N, Haymaker W, Custer RP. Heat stroke, a clinicopathologic study of 125 fatal cases. Milit Surg 1946;99:397449.
4. Kew MC, Bersohn I, Seftel HC, Kent G. Liver damage in heatstroke. Am J Med 1970;49:192-202.

5. Rubel LR, Ishak KG. The liver in fatal exertional heatstroke. Liver 1983;3:249-260.

6. Bianchi L, Ohnacker H, Beck K, Zimmerh-Ning M. Liver damage in heatstroke and its regression: a biopsy study. Hum Pathol 1972;3:237-248.

7. Wills EJ, Findlay JM, McManus JPA. Effects of hyperthermia therapy on the liver: II Morphological observations. J Clin Pathol 1976;29:1-10.

8. Vescia FG, Peck OC. Liver disease from heatstroke. Gastroenterology 1962;43:340-343.

9. Herman RH, Sullivan BH Jr. Heatstroke in jaundice. Am J Med 1959;27:154-157.

10. Shibolet S, Lancaster MC, Danon Y. Heatstroke: a review. Aviat Space Environ Med 1976;47:280-301.

11. Schrier RW, Henderson HS, Tischer CG, Tannen Rl. Nephropathy associated with heat stress and exercise. Ann Intern Med 1967;67:356-376.

Received July 5, 1990. Accepted November 17, 1990.

Address requests for reprints to: David H. Van Thiel, M.D., Department of Surgery, University of Pittsburgh, 3601 Fifth Avenue, Falk 5-C, Pittsburgh, Pennsylvania 15213. 